\section{A LONG-TERM VIEW OF FINANCIAL REGULATION}

Fundamental flaws in the UK's system of financial regulation were exposed by the 2007-09 financial crisis, and the government has embarked on radical reforms to the current regime. The Financial Services Bill, scheduled to reach the statute book by the end of this year, will implement a new structure. This is based around the establishment of the Financial Policy Committee (FPC) within the Bank of England to monitor and respond to systemic risks, and the creation of two new regulators in the form of the Prudential Regulation Authority (PRA) to oversee the day-to-day supervision of financial institutions, and the Financial Conduct Authority (FCA) to take responsibility for monitoring the conduct of business.

Other initiatives have surfaced over the past few months. In June the Business Secretary, Vince Cable, announced a package of corporate governance measures designed to tackle the city bonus culture which are scheduled to be implemented by October 2013. Also issued in June, a white paper, Banking reform: delivering stability and supporting a sustainable authority, $\mathrm{Cm}$ 8356, set out the government's plans for implementing the recommendations of the Independent Commission on Banking which, among other measures, will entail ring-fencing retail and investment banking.

This was followed in July by a Treasury consultation, Sanctions for the directors offailed banks, which contained plans to strengthen the accountability of bank directors by amending the Financial Services and Markets Act 2000 (FSMA) to introduce a rebuttable presumption that a director of a failed bank is not suitable to be approved by a regulator to hold a similar future position. To back this up, consideration is being given to the introduction of criminal sanctions for a new offence of serious misconduct in the management of a bank. August saw the arrival of another consultation, Financial sector resolution: broadening the regime, Cm8419, which addressed the issue of how to deal with the risks posed by the failure of systemically important organisations other than banks.

All those involved with the reform of financial services regulation are aware that although the accountability of those in senior positions can be influenced by legislative intervention, there needs to be a change in long-term thinking within the financial markets to avoid a repeat of mistakes made in the recent past. Professor John Kay was asked by the Department for Business, Enterprise and Skills (BIS) to address this and other issues by examining the effect of the UK equity markets on the competitiveness of UK business, and his final review, UK equity markets and long-term decision-making, appeared on July 23.

The terms of reference for the review were wide, and its proposals reflect this. They concentrate on restoring relationships of trust and confidence in the investment chain, and establishing high level statements of good practice for its key players such as asset holders, asset managers and company directors. The quality of engagement by investors with companies needs to be

\section{Articles}

Judah Benjamin: the Confederate barrister

Derivative claims under UK company law and some related provisions of German law

Institute News

\section{Articles (cont'd)}

Transitional justice and the transition to democracy: looking at the past to gain a better perspective for the future

The authority of a truncated arbitral tribunal straight path or puzzle?

improved, emphasising and broadening the existing concept of stewardship. "Misaligned incentives" in the remuneration practices of company executives and asset managers need to be tackled, along with the pressures for short-term decision making that arise from excessively frequent reporting of financial and investment performance (including quarterly reporting by companies), and from an over-reliance on particular metrics and models for measuring performance, assessing risk and valuing assets.

Professor Kay presents his findings in the form of proposals, 10 principles to be followed by all participants in the equity investment chain, and 17 recommendations for reform. He pays particular attention to short-termism, a key underlying issue in UK equity markets, which is characterised in his report as: "both a tendency to underinvestment, whether in physical assets or in intangibles such as product development, employee skills and reputation with customers, and as hyperactive behaviour by executives whose corporate strategy focuses on restructuring, financial re-engineering or mergers and acquisitions at the expense of developing the fundamental operational capabilities of the business."

Professor Kay's analysis of his subject has attracted praise, although the review has faced criticism for a perceived lack of substance. By undertaking an in-depth analysis of the problems faced by the UK equity markets Professor Kay has sought to reveal the underlying mindset which has created them. The key question is whether policy makers and regulators both nationally and internationally will be able to make effective use of the tools at their disposal in order to exert a stronger influence in the long-term over the way financial markets operate.

Julian Harris

Deputy General Editor, Amicus Curiae

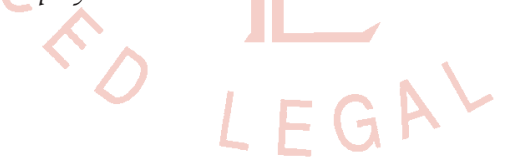

